\title{
Formación ética y ciudadana. Vicisitudes de la transformación curricular en la Patagonia Argentina
}

\author{
Ethical and Civic Education. Difficulties during \\ the Curricular Reform in Argentine Patagonia
}

\author{
Isabelino A. Siede \\ Elizabeth Guglielmino \\ Julia Alcain \\ Gabriela Fernández \\ Diana Guinao ${ }^{1}$
}

\section{Resumen}

¿Qué tipo de educación ética y ciudadana ofrecen efectivamente las escuelas? En este artículo se analizan las prescripciones curriculares de formación ética y ciudadana en las escuelas de educación básica de la Patagonia Argentina, y sus relaciones y contradicciones con las prácticas escolares de educación moral. Se indaga el proceso de definición del área en el contexto de la reforma educativa de los años noventa y busca reconstruir su modalidad de incorporación en el diseño curricular provincial de Santa Cruz, como expresión de las intenciones explícitas e implícitas de esa política curricular. A través de grupos focales y entrevistas a docentes de diferentes escuelas públicas y privadas de tres localidades del norte santacruceño, se analizan las descripciones, valoraciones y expectativas de los docentes sobre sus prácticas de enseñanza en el terreno moral, así como también las posibles causas de las distancias y contradicciones entre las políticas de enunciación curricular y las propuestas formativas que ofrecen las escuelas.

Palabras clave

Ética, educación ciudadana, educación moral, currículo, nivel primario.

\section{Abstract}

What type of ethical and civic education is effectively provided at school? This article analyzes the curricular prescriptions of Ethical and Citizenship Education in primary schools of the Argentine Patagonia, as well as its relations and contradictions with the schoolpractices of moral education It inquires the process of definition of the area in the context of the Educational Reform in the 90s. Also, it pursuits to remake the way it was incorporated in the provincial curriculum design. Throughout focus groups and interviews to teachers from different public and private schools of three towns from de north of Santa Cruz, we analyze the descriptions and expectative of the teachers about their teaching practice in the moral area, as well as the possible causes of the differences and the contradictions between the policies of the curricular statement and educational proposals offered at school.

\section{Keywords}

Ethics citizenship education, moral education, curriculum, primary level.

Artículo recibido el 27 de octubre de 2014 - aprobado el 20 de noviembre de 2014

1 Unidad Académica Caleta Olivia de la Universidad Nacional de la Patagonia Austral. 
Este trabajo presenta un primer avance de una investigación actualmente en curso $^{2}$ que analiza las prescripciones curriculares de formación ética y ciudadana en la provincia de Santa Cruz (Argentina), y sus relaciones y contradicciones con las prácticas escolares de educación moral. A través de grupos focales y entrevistas se ha podido recoger una variedad de valoraciones, expectativas y metodologías que marcan una distancia considerable entre los supuestos de la prescripción curricular y el currículo real del nivel primario en tres localidades del norte santacruceño. Al relevar las descripciones y justificaciones de los docentes sobre sus prácticas de educación moral, se puede apreciar una fuerte impronta moralista, que da continuidad a algunas tradiciones civilizatorias, higienistas y homogeneizantes desarrolladas desde los orígenes del sistema educativo provincial. Los enunciados del diseño curricular, que pretendían la formación de sujetos autónomos, críticos y solidarios, entre otros adjetivos, parecen haber tenido escasísimo impacto en las prácticas. No se advierte la presencia de un trabajo de articulación institucional que sirva de encuadre, por lo que queda supeditado a las representaciones y creencias que tiene cada uno de los docentes respecto del tema. Por su parte, el diseño curricular jurisdiccional no parece ser un documento de trabajo de uso corriente en la vida cotidiana de la escuela.

A continuación, haremos una breve reseña del proceso curricular desarrollado en Argentina en los últimos veinte años, apreciaremos las decisiones de prescripción curricular de la provincia de Santa Cruz y analizaremos el testimonio de docentes en ejercicio acerca de su trabajo habitual sobre esta temática. Por último, haremos una evaluación del recorrido investigativo y de las alternativas ulteriores, junto con una valoración de sus implicancias en las discusiones curriculares de la región.

2 Proyecto "Situación actual de la formación ética y ciudadana en las escuelas primarias del norte de Santa Cruz" (Código: 29/B148-1), radicado en la Unidad Académica Caleta Olivia de la Universidad Nacional de la Patagonia Austral. Director: Isabelino Siede; Codirectora: Elizabeth Guglielmino; Integrantes: Julia Alcain, Gabriela Fernández y Diana Guinao. Periodo: 2013-2016.

\section{La educación ciudadana en el proceso de renovación curricular en Argentina}

La intención de educar al soberano fue la piedra fundamental sobre la cual se edificó el sistema educativo argentino y, particularmente, el nivel primario (Tedesco, 1986; Puiggrós, 1994; Lionetti; 2007). Si los fundamentos político-pedagógicos de tal énfasis surgieron de la decisiva pluma de Domingo F. Sarmiento, su expresión institucional se plasmó en la Ley 1420 del año 1884. Bajo el lema de "civilizar a los bárbaros", la educación ciudadana cobró un fuerte sesgo moralista, que suponía un proceso de transculturación, por el cual los hijos de los nativos serían socializados según parámetros de cuño europeo. En las décadas siguientes, las enseñanzas morales escolares recibieron un fuerte influjo del higienismo social, que delimitaba las conductas normales esperables y las anormales repudiables en los niños. Al mismo tiempo, en las primeras décadas del siglo XX, la afluencia de una enorme masa inmigrante provocó una reacción defensiva de las élites, que propiciaron un vuelco hacia la educación patriótica. A través de rituales periódicos y relatos que emulaban un pasado glorioso, inducían la identificación emocional de los niños con el país que acogía a su familia, en reemplazo de identificaciones previas con la lengua, la historia y los símbolos heredados de sus padres (Siede; 2007). De la confluencia de vertientes civilizatorias, higienistas y patrióticas se fue conformando un conjunto de prácticas y criterios de educación moral escolar, que caracterizó la socialización de la primera mitad del siglo XX y aún tiene largas repercusiones en dinámicas institucionales actuales. Según Raúl Díaz (2001), se fue configurando un nosotros colectivo

[...] que afirma determinadas pautas culturales, modos de vida, y concepciones del mundo social [...] para garantizar identidades culturales y sociales compatibles con el Estado que se va configurando. Nacionalizar el territorio, la cultura, el idioma, y la educación (entre otras cosas) implicó e implica situar a los "otros" en lugares de "integración" subordinada, y al mismo tiempo de exclusión económica y social (pp. 41-42). 
Formación ética y ciudadana. Vicisitudes de la

transformación curricular en la Patagonia Argentina

Isabelino A. Siede, Elizabeth Guglielmino, Julia

Alcain, Gabriela Fernández y Diana Guinao

Desde mediados de siglo, sin embargo, las vicisitudes políticas e ideológicas que tiñeron el derrotero nacional incluyeron diferentes voces de impugnación de la educación moral y cívica que brindaba la escuela. La influencia escolanovista y las corrientes pedagógicas renovadoras pugnaron por reducir o desterrar modalidades de adoctrinamiento $\mathrm{y}$ adiestramiento, crecientemente valoradas como ilegítimas. La última dictadura militar, en su afán de disciplinamiento social ${ }^{3}$, volvió a enfatizar los lineamientos de una educación moral conservadora y homogeneizante. Por eso, durante la transición democrática de los años 1980, en la tarea de desmontar los dispositivos represivos de las instituciones, tanto las autoridades políticas como los equipos docentes sometieron a revisión los lineamientos de la educación moral, que quedó relegada y deslucida, ajena al discurso oficial.

En la década siguiente se inició un acelerado proceso de reforma educativa caracterizado, principalmente, por completar la transferencia de todas las dependencias del sistema educativo (salvo las universidades) a la órbita de los gobiernos provinciales; redefinir los niveles y ciclos de la estructura escolar y establecer nuevos parámetros curriculares. A partir de las leyes de transferencia de las instituciones educativas del Estado nacional a las provincias y la Ley Federal de Educación, aprobada en 1993, el Consejo Federal de Cultura y Educación (CFCyE) asumió la responsabilidad de establecer contenidos básicos comunes (CBC) para todo el país, que servirían como parámetro para la definición de diseños

3 Existen discusiones sobre el orden de prelación entre las múltiples causas que llevaron a la interrupción del orden institucional argentino en marzo de 1976. Algunos historiadores priorizan los motivos políticos y otros los de orden económico, aunque no son pocos los que enfatizan los aspectos culturales que llevaron a que las fuerzas armadas buscaran restaurar un orden que consideraban natural. En declaraciones realizadas muchos años después, el general Videla, expresidente de facto, sostuvo: "[...] nuestro objetivo era disciplinar a una sociedad anarquizada; volverla a sus principios, a sus cauces naturales" (Reato, 2012, p. 155). Lo que el dictador juzga a la distancia como "sociedad anarquizada" era la expresión de la participación juvenil, la lucha por mayor justicia en las relaciones laborales y la irrupción de nuevas configuraciones familiares y amorosas que surgían de las impugnaciones al poder patriarcal. curriculares compatibles ${ }^{4}$. Esos contenidos fueron aprobados en 1994 por el Consejo Federal de Cultura y Educación e incluían un capítulo dedicado a la formación ética y ciudadana. Allí se afirmaba:

La sociedad demanda a la escuela que forme personas íntegras y buenos ciudadanos, que eduque para la vida plena de cada uno y de todos, y que lo haga conforme a su dignidad de persona y a las necesidades del mundo de hoy. [...] Se trata de saber ser persona y sujeto social, saber respetar y valorar a los otros, el orden constitucional y la vida democrática, saber defender los derechos humanos y preservar el medio natural, saber analizar los aspectos morales de la realidad y vivirlos, para insertarse responsablemente en un mundo complejo y atravesado por transformaciones y crisis profundas. (CFCyE, 1995, pp. 337-338).

Este capítulo, que reunía tres bloques denominados "Persona", "Valores" y "Normas", junto a los de "Contenidos procedimentales" y "Contenidos actitudinales" semejantes a los demás capítulos, provenía de los llamados "Temas transversales", que habían llegado al debate pedagógico argentino a partir de bibliografía publicada en España y fueron mencionados explícitamente por el CFCyE al demandar la redacción de los CBC:

Los contenidos transversales son aquellos que recogen demandas y problemáticas sociales, comunitarias o laborales relacionadas con temas, procedimientos o actitudes de interés general. Como es usual, su tratamiento requiere un encuadre ético que desarrolle actitudes cuidadosas y de valoración hacia la propia persona, la comunidad y el ambiente natural. Requieren del aporte de distintas disciplinas y de una lógica espiralada, ya que pueden ser abordados con distintos niveles de complejidad y profundidad según los saberes previos, los intereses y otras cuestiones que solo es posible precisar en el nivel de cada institución escolar. Por eso parece conveniente, que en el diseño curricular, los contenidos transversales

4 Según Puiggrós (1997), “hay que pensar la política educativa neoliberal ya no en términos de una enorme operación de descentralización privatizadora, sino como un gran operativo de centralización de los dispositivos productores de cultura y transmisores de saberes en unas pocas manos, que son las mismas que se lavan de la responsabilidad del financiamiento" (p. 124). 
se encuentren clara y diferenciadamente especificados, aunque luego se trabajen en los horarios previstos para áreas o disciplinas, o en los talleres interdisciplinarios, o a través de proyectos especiales (CFCyE, 1994).

En consecuencia, el documento aclaraba que la existencia de un capítulo de formación ética y ciudadana en los CBC no implicaba que debiera existir en los diseños provinciales un área de enseñanza con ese nombre, aunque establecía la obligatoriedad de enseñar los contenidos allí reunidos. Estos contenidos vinculados con la ética y la ciudadanía aportaban algunas novedades, pero también buscaban visibilizar prácticas de enseñanza que continuaban circulando por el llamado currículo implícito u oculto, como modalidades de adoctrinamiento moralizante (Jackson, Boostrom y Hansen, 2003).

La aprobación de los $\mathrm{CBC}$ suscitó un debate inesperado con la Iglesia católica, que había sido consultada oportunamente pero vio reducida su influencia en el documento final. Tras la movilización de los sectores más recalcitrantes del espectro católico y en vísperas de las elecciones presidenciales, el CFCyE aceptó todas las sugerencias episcopales, tras lo cual decidió una nueva edición de los CBC pocos meses después de haber publicado la primera. Gran parte de las correcciones afectaron el capítulo de formación ética y ciudadana, por lo que Carlos Cullen, quien había coordinado su escritura, presentó su renuncia. El texto quedó sesgado por una visión confesional, a través de sutiles y no tan sutiles modificaciones.

En formación ética y ciudadana, las correcciones lograron, entre otros cambios, que se mencionara explícitamente como atributos de la persona su "trascendencia" y su capacidad de "relacionarse con Dios", y la aproximación a las reflexiones religiosas solo como "enriquecimiento" y no como "contrastación y enriquecimiento" según el texto original. (Hillert, 2011: 159).

Cullen, quien había asumido originalmente la responsabilidad institucional de enunciar los contenidos, tomó distancia prontamente de la prescripción acordada y denunciaba poco después:
Preparar para vivir en una sociedad globalizada es preparar para una visión crítica de la globalización, y no para adaptarse a la exclusión o a la moral competitiva del modelo económico del capitalismo salvaje. La ciudadanía en la sociedad globalizada es una ciudadanía que luche por el ingreso equitativo, y no por las exclusiones; por los derechos humanos, y no por las democracias puramente formales; por la participación ciudadana y no meramente por la aceptación, más o menos pasiva, de ciertos parámetros. (Cullen, 1996, p. 78).

Según esta visión, el ingreso del área a la escuela debería servir como puntal de adopción de actitudes críticas ante la desigualdad social creciente y erigirse como alternativa a la moral adaptativa heredada de las tradiciones escolares previas. El riesgo también era alto, pues la prescripción curricular habilitaba la enseñanza sobre contenidos ausentes en la formación docente y aptos para convalidar el orden social si eran encarados con liviandad y escaso sustento. ¿Qué demanda resolvía la escuela con esta área? ¿La del gobierno que buscaba convalidar el orden social derivado de sus políticas? ¿La de la Iglesia que pretendía dar continuidad a su prédica al amparo de las instituciones públicas? Tras la declamada intención de formar una ciudadanía crítica arreciaban otros riesgos:

El peligro de entender esta demanda en términos de legitimar la exclusión y profundizar la segmentación educativa puede ser muy grande. Las escuelas con población excluida y con condiciones de modernización débil o depotenciada pueden tender a legitimar una escala de valores para vivir en la exclusión, en la ignorancia y para contener la violencia social que estas situaciones generan. Normalmente, estas escuelas arman sus proyectos sobre la base de cuestiones "supletorias", descargadas en las instituciones por los vacíos de políticas públicas, como puede ser dar de comer a los niños, contener la violencia juvenil, crear un microclima de buena conducta social y de cuidado del medio ambiente y de la salud. [...] Insisto en este tema porque la demanda a la escuela puede querer decir, simplemente, dar una formación ética y ciudadana que haga gobernable la sociedad, 
Formación ética y ciudadana. Vicisitudes de la transformación curricular en la Patagonia Argentina

Isabelino A. Siede, Elizabeth Guglielmino, Julia Alcain, Gabriela Fernández y Diana Guinao

a pesar de las injusticias excluyentes del modelo y a pesar del creciente desempleo, marginación y violencia. (Cullen, 1996, pp. 82-86).

Tras la definición federal de los contenidos, cada jurisdicción inició la tarea de formular sus propios diseños curriculares. Desde el Ministerio de Cultura y Educación de la Nación supervisaron esa tarea los especialistas que reemplazaron a Cullen: en primera instancia Juan Esteban Belderrain y, desde 1999, Gustavo Schujman.

\section{Enfoque de la educación ciudadana en la prescripción curricular de Santa Cruz}

La provincia de Santa Cruz demoró bastante la elaboración de su diseño curricular, que se redactó en los primeros años del siglo XXI. Comenzó a gestarse en 2002 y fue publicado y enviado a las escuelas al comenzar el ciclo lectivo de 2004, en un contexto político e institucional muy diferente del que había acompañado la elaboración de los $\mathrm{CBC}^{5}$.

En ese documento, la elaboración del capítulo de formación ética y ciudadana estuvo a cargo de María Laura Baranda, Gladis Quiroz y Juan Carlos Marichelar, quienes figuran como autores. Según Quiroz ${ }^{6}$, los tres tenían experiencia docente en el nivel secundario ${ }^{7}$, aunque fueron convocados para escribir la prescripción curricular de la EGB ${ }^{8}$.

Este capítulo del diseño curricular provincial reúne aportes de diversas tendencias teóricas

5 El gobierno de Carlos Menem, bajo el cual se habían aprobado los CBC, terminó en 1999. Le sucedió la gestión de Fernando de la Rúa, que finalizó intempestivamente en diciembre de 2001, en un contexto de fuerte crisis económica y política. Tras un tiempo de zozobra institucional, el Congreso de la Nación designó presidente interino a Eduardo Duhalde. En 2003 hubo nuevas elecciones generales y resultó electo Néstor Kirchner, quien gobernó hasta 2007. Kirchner había ocupado anteriormente el cargo de gobernador de Santa Cruz. En líneas generales, su gobierno impulsó un cambio de rumbo respecto a los anteriores $y$, aunque provenía del mismo partido, impugnó las orientaciones políticas e ideológicas de Carlos Menem en los años 1990.

6 Esta y las siguientes referencias a Gladis Quiroz corresponden a la entrevista que le realizara Isabelino Siede el 30 de octubre de 2013.

7 Correspondiente a las edades teóricas de 13 a 17 años.

8 Correspondiente a las edades teóricas de 6 a 14 años. sin dar cuenta de sus tensiones y contradicciones internas. De ese modo, yuxtapone visiones difícilmente compatibles desde el punto de vista filosófico, pedagógico y didáctico. Un ejemplo de este rasgo es que el texto se manifiesta laico y pluralista, pero la portada del área cita expresamente el segmento del Preámbulo de la Constitución provincial que alude a la "protección de Dios". El enfoque filosófico del diseño oscila entre una visión racionalista de la ética, heredera de la tradición kantiana, y el respeto a una diversidad valorativa que, en cierto modo, se concibe como estadio inferior o periférico de una "ética mínima" de carácter universal. En esa línea, distingue "el abordaje de los contenidos" de la "enseñanza diversa":

Lo precedentemente señalado lleva a considerar el desarrollo de este espacio curricular por dos caminos:

Uno es la búsqueda de los mecanismos necesarios para lograr el abordaje de los contenidos, es decir, enseñar a distinguir la ética como disciplina racional, y la moral como el conjunto de valores y normas que se conforman como una tradición social determinada o como marcos referenciales para la toma de decisión y las acciones de individuos determinados. La ética puede definirse como una reflexión sobre el origen, la articulación y el fundamento de los conjuntos de normas, valores y costumbres de los grupos humanos. La moral es el conjunto de normas, valores y costumbres que rigen en un grupo (ya sea este social, cultural, étnico, religioso). Siguiendo esta definición, en una determinada sociedad pueden convivir morales diversas. Es lo que algunos autores llaman "ética mínima" aquella que permite, por lo menos la convivencia pluralista y democrática desde diversas morales sociales e individuales teniendo en cuenta los intereses de todos los afectados en pie de igualdad basada en la justicia, ejemplo: los derechos humanos.

El otro es generar una enseñanza diversa, es decir, que no es inculcar o imponer una moral o determinados valores que conforman el patrimonio de esa moral, es enseñar a razonar moralmente, empleando principios éticos de fundamentación 
de los valores y de las normas. Es enseñar a resolver, por el diálogo argumentativo los conflictos de valores, es enseñar a respetar las diferencias y a construir proyectos comunes, por pequeños que sean, basados en los principios racionales y en el diálogo argumentativo (Baranda, Quiroz y Marichelar, 2004, p. 3).

Según rememora Quiroz, la intención de los autores era evitar el adoctrinamiento y favorecer un trabajo didáctico activo tanto del docente como de los alumnos:

[...] trabajamos mucho sobre el papel del docente en el aula: cómo tenía que actuar el docente, para que esto no se convierta desde una moralina, de inculcar desde lo moral, que sea una reflexión crítica de los temas. Entonces se hablaba de la neutralidad beligerante9, del docente mediador, del docente que guía al alumno y que el alumno sea el que logre discernir, el que llegue a debatir, el que llegue a poder sostener una postura.

Quiroz no recuerda con exactitud la bibliografía más relevante que tenían en cuenta al redactar los lineamientos, pero enfatiza el rol de Carlos Cullen como referente general: "Cullen era creo que donde estaba la base de todo cuando trabajábamos. Todo lo que era la ética y lo que era de los espacios públicos y cuando hablábamos de ciudadanía y todo. Cullen fue una de las bases".

Quiroz menciona una discusión con Gustavo Schujman sobre la noción de trascendencia, cuando este supervisaba la redacción de la prescripción curricular provincial desde el Ministerio de Educación de la Nación.

Con Gustavo Schujman, que él estaba en el equipo de Nación, una vez tuvimos una entrevista [...] acá en la provincia, en Río Gallegos. Venía precisamente a leer y a interactuar con nosotros sobre el diseño. [...] El de trascendencia fue un concepto que se debatió bastante. Porque nosotros planteábamos la trascendencia desde un proyecto de vida, vamos a decir, un proyecto que se iba conformando

9 Alude a una categoría acuñada por Jaume Trilla (1992), a la que probablemente accedieron a través de textos de Cullen (1996), quien la menciona en repetidas ocasiones. el niño, el adolescente, y por ahí la postura de él era que transcendente daba más para lo espiritual, lo ascendente, lo que está más allá, algo superior.

El debate tiene relevancia si se toma en cuenta que la noción de trascendencia había sido una de las incorporadas por la jerarquía católica a los CBC. En este caso, los especialistas provinciales pugnaban por mantenerla, mientras el referente nacional prefería obviarla.

La prescripción curricular es ambigua en lo referente a la inserción práctica de esta área en el proceso formativo que ofrecen las escuelas: está teñida del enfoque de la transversalidad, característico de la época en que fue escrito, con alusiones poco específicas al modo en que se concibe esa transversalidad.

Se crea el área de formación ética y ciudadana y se sistematizan sus contenidos. Existe, en primer lugar, un núcleo de contenidos específicos que merecen un tiempo y espacio propio para su enseñanza (entre ellos se puede mencionar: el diálogo argumentativo, los aspectos morales de la acción humana y el estado de derecho). En segundo término, se puede reconocer la presencia de contenidos de formación ética y ciudadana durante el desarrollo de los contenidos de otras áreas (temas como por ejemplo la conquista de América: Ciencias Sociales, o las variedades lingüísticas: lengua). Asimismo, durante la vida cotidiana, tanto en la escuela como en la comunidad, se presentan permanentemente situaciones que pueden ser puntos de partida para el desarrollo sistemático de algunos contenidos del área (como la resolución de conflictos grupales, la necesidad de practicar la toma de decisiones o la participación en acciones comunitarias). (Baranda, Quiroz y Marichelar, 2004, p. 2).

Un rasgo particularmente relevante del diseño provincial del área es su escaso regionalismo ${ }^{10}$ : hay muy pocas alusiones al contexto sociocultural local y pocas señales indican que se trata del diseño curricular santacruceño. Sí hay algunas apreciaciones globales de la coyuntura histórica, como la siguiente:

10 Esta consideración no implica valorar el regionalismo como una virtud, sino que llama la atención que se trata de una prescripción formulada al margen de cualquier rasgo local y enunciada para un contexto abstracto 0 etéreo. 
Formación ética y ciudadana. Vicisitudes de la

transformación curricular en la Patagonia Argentina

Isabelino A. Siede, Elizabeth Guglielmino, Julia

Alcain, Gabriela Fernández y Diana Guinao

Con la recuperación de la vida democrática aparece con claridad la necesidad de enseñar a vivir en democracia, a defenderla, a valorarla, para lo cual es necesario conocerla y conocerla bien entendiendo sus desafíos actuales, ante la evidencia de la crisis de las instituciones sociales fundantes del orden y el progreso, como la familia y el estado y ante la fuerte crisis de valores, las desigualdades en el desarrollo, la interculturalidad, la comunicación masiva, el fracaso del Estado de Bienestar y la retirada de las ideologías y de las utopías. (Baranda, Quiroz y Marichelar, 2004, p. 2).

Como contrapartida, el diseño invita a contextualizar el área, aunque ofrece escasas herramientas para realizar esa tarea:

El área de formación ética y ciudadana permite y requiere una contextualización específica en cada comunidad escolar, a fin de atender las necesidades y demandas particulares de sus alumnos. La contextualización plantea desafíos nodales para los docentes y la organización escolar:

Revisar activa y permanentemente la coherencia entre pensar, sentir y hacer de todos los adultos que están en contacto con los alumnos.

Avanzar en los niveles institucionales de criticidad, creatividad, solidaridad y compromiso.

Establecer encuadres institucionales de justicia y solidaridad, que permitan la justificación argumentativa de las acciones y decisiones pedagógicas adoptadas. (Baranda, Quiroz y Marichelar, 2004, pp. 2-3).

Ese rasgo de apertura, con la expectativa de que cada institución y cada equipo docente contextualizaran los contenidos y las modalidades de enseñanza, hoy es evaluado con rasgos autocríticos por parte de Quiroz, consciente de que ese proceso no pudo llevarse a cabo:

Inclusive en los alcances nos parecía, en ese momento, que teníamos que dejarle la posibilidad al docente de poder tener contenidos amplios como para que pueda seleccionar y elegir de acuerdo a la realidad que tenía. Precisamente por esa transversalidad que había en primero y segundo ciclo. [...] Si hoy yo me pongo a pensar y a mirar el diseño con la experiencia esta del diseño de secundaria, puedo decir que, por ahí, fueron contenidos o alcances demasiado amplios y generalizados, que hizo que el docente de acuerdo al perfil que tenemos, que son muchos en la Provincia, los temas, los contenidos elegía de acuerdo a su perfil y no de acuerdo a la integración de la disciplina. [...] En ese momento nos parecía que era lo mejor cómo estaba estructurado el diseño del PEI, para que se empiece a trabajar formación ética y ciudadana y para después realmente darle la solidez que tenía que tener. Para ese momento, pudo haber estado acertado, pero después, a medida que fueran pasando los años, yo como profesora de formación ética y ciudadana me voy del lado del docente, me di cuenta de que generalizamos demasiado. Nos faltó un poco más de especificidad en los contenidos. Más allá de toda la fundamentación, de todas las orientaciones que tiene el diseño, muy bueno, pero me parece que nos faltó un toque, otra impronta.

Abrumados por la novedad de los cambios curriculares, la expectativa de los docentes era recibir una capacitación específica que complementara su formación de base y ofreciera orientaciones más concretas para la práctica, según menciona Quiroz:

Como mis colegas de la EGB sabían que yo estaba en el diseño, lo que recuerdo es que, por ahí, también decían que si bien ellos trabajaban algunos temas así aislados o solitarios, también necesitaban mucha capacitación, mucha formación porque no sabían cómo encararlo, cómo darlo, para que no sean los temas abstractos, sino que les sirva para los chicos. Vamos a decir, era toda una novedad para ellos y los miedos de todos los comienzos, ¿no?

Según la autora que entrevistamos, esa expectativa quedó insatisfecha, pues el equipo que redactó el diseño terminó sus funciones al entregarlo y no tuvo incidencia en la capacitación posterior:

Sé que se hizo un proceso de socialización, de "baja"11 de diseño. Yo estaba en la EGB3, ejer-

11 Se trata de una expresión coloquial, proveniente del ámbito político: bajar el diseño es llevarlo a las bases, como instructivo, a través de instancias de explicitación y orientación. Esta traslación de la 
ciendo formación ética y ciudadana y me hicieron ir una vez que presentaron el diseño. Pero no lo hicimos nosotros. [...] En mi escuela, al menos, una sola vez se presentó. [...] Faltó la socialización, faltó el trabajo, la mesa de trabajo con los docentes, la socialización posterior, inclusive, la capacitación faltó. Que si no era la capacitación pagada no teníamos o había capacitaciones aisladas que se enteraban pocos, pero no sé si eso pasó en toda la provincia o desde la realidad que visualicé desde mi lugar, ¿no? Yo desde 2004 no estuve más en el equipo.

Como resultado de ese proceso trunco, en su mirada retrospectiva, Quiroz evalúa que el área se implementó muy parcialmente:

En varias escuelas se implementaron proyectos donde uno veía que se trabajaban estos temas transversales. Desde proyectos institucionales ya se aplicaban estos proyectos, implementados ya desde el PEI12. Desde el primer día la institución organizaba ese proyecto y participaban, es decir, interdisciplinariamente las disciplinas. En las aulas no le puedo decir mucho, porque de acuerdo con mi experiencia en la escuela se seguía dando, vamos a decir, en quinto grado, la Constitución... No había una articulación. Me parece que faltó esa articulación. Sé que en algunos colegios lo hicieron. Después, a lo lejos uno escucha que se hicieron proyectos pero no sé si partiendo desde lo que era el objetivo nuestro de formación ética y ciudadana, ¿no? [...] En primero y segundo ciclo13, yo no soy de esos niveles y a lo mejor peco de decir si se trabajó o no, y no quiero herir susceptibilidades tampoco, ¿no? [...] Se subestimó demasiado la formación ética y ciudadana, me parece, y solamente empezaron a trabajar temas emergentes o temas que surgen en el momento y, por ahí, se olvidaron del fundamento teórico o, vamos a decir, la especificidad que se le tiene que dar.

bajada de línea del ámbito político al contexto educativo expresa una concepción aplicacionista y vertical del currículo, aparentemente contrapuesta a la socialización que menciona repetidas veces.

12 PEl significa "Proyecto Educativo Institucional" y alude a que cada escuela debía elaborar una propuesta educativa y definir sus contenidos transversales, en ejercicio de su autonomía.

13 El primer ciclo de la Educación General Básica abarcaba las edades teóricas de 6 a 8 años y el segundo ciclo, de 9 a 11 años.
En líneas generales, el ingreso del área a la prescripción provincial parece haber sido un experimento trunco, en el que la gestión de gobierno impulsó una novedad curricular sin asumir la responsabilidad de darle cauce, proveer de herramientas y realizar un seguimiento evaluativo.

Según hemos analizado, pueden objetarse los fundamentos teóricos y los lineamientos pedagógicos de la prescripción curricular, redactada por un equipo con escaso trabajo previo y directivas poco claras, que se disolvió apenas entregó el texto solicitado. Asimismo, es claro que el ingreso al currículo de una nueva área de enseñanza requería algún plan de capacitación y desarrollo curricular, para acompañar a docentes que no habían recibido orientaciones para ello en su formación básica. Sin embargo, solo se envió a las escuelas un documento normativo en el que la nueva área ocupaba las páginas finales. Para bien o para mal, el área llegó huérfana a las aulas, lo cual preanunciaba un destino poco promisorio.

\section{Testimonios de los docentes sobre su tarea}

A través de grupos focales y entrevistas hemos podido recoger una variedad de valoraciones, expectativas y metodologías de enseñanza que marcan una distancia considerable entre los supuestos de la prescripción curricular y el currículo real del nivel primario, en tres localidades del norte santacruceño. En total, 27 docentes en ejercicio participaron de 11 grupos focales ${ }^{14}$ realizados en las localidades de Caleta Olivia, Cañadón Seco y Pico Truncado, entre agosto y diciembre de 2013. La muestra está conformada por maestros de grado de 22 escuelas (17 públicas y 3 privadas; 20 de educación común y 2 de educación especial), de primero y segundo ciclo del nivel primario. Los grupos focales se realizaron en la sede de alguna de las escuelas invitadas o en la universidad y participaron, en cada caso, aquellos docentes que estaban disponibles en el momento de la convocatoria. En líneas generales, la concreción

14 Cada grupo focal fue nombrado con una letra y cada participante con un número. En los fragmentos que se transcriben más adelante, se identifica a cada hablante mediante la sigla conformada por esa letra y ese número específicos. 
Formación ética y ciudadana. Vicisitudes de la

de los encuentros resultó bastante dificultosa por recurrentes malentendidos administrativos y variadas contingencias que expresan el marco habitual de la zona: cortes en el suministro de agua, protestas sociales con cortes de ruta, suspensión de clases por falta de calefacción, etc. Estas anomalías parecen ser el contexto cotidiano del trabajo educativo, frecuentemente expuesto a la fragilidad de la coyuntura.

En este trabajo, nos interesa analizar cuatro cuestiones básicas: a) las visiones de los docentes sobre las comunidades con las cuales trabajan; b) los propósitos y contenidos que consideran más relevantes en la formación ética y ciudadana; c) las metodologías que adoptan para la enseñanza, y d) los principales problemas que encuentran en su trabajo. Analizamos estas cuestiones de manera conjunta, pues los testimonios las enhebran entre sí, para luego diferenciar las conclusiones.

Algunos fragmentos permiten reseñar las miradas predominantes de los docentes sobre la población de la escuela en la que se desempeñan:

En esta escuela he observado que [...] son papás que tienen diferentes niveles económicos. Los que están en riesgo son menos, o sea, hay una población bastante alta de papás que pueden solventar los gastos de la escuela, son papás que se acercan a la institución, que participan en los talleres, que se observa mayoritariamente un acompañamiento de la familia para con los nenes (K1).

La mayoría son familias con un buen pasar económico, aunque también hay algunos desfasajes económicos en algunos chicos, pero son los menos. Sí, son los menos, fuera de eso cubren, digamos, las expectativas generales que permite la escuela (I2).

Yo estoy solo con uno de los primeros, pero es variadito en cuanto a lo que veo culturalmente. Económicamente hay bastantes necesidades. [...]Vos quizás los ves afuera o en la casa y no la hay, pero yo he trabajado en cinco escuelas y te puedo asegurar que adentro de la escuela te da la sensación que todos tienen necesidades. No traen materiales, no tienen cosas, tienen hambre, se desesperan por un pedacito de pan, se desesperan en el kiosco, pero por ahí lo encontrás en la calle o los vienen a buscar y viene en terribles vehículos, los ves de otra manera. Entonces yo no sé por qué en la escuela se ve esa parte que quizás no es real, pero es la que nos toca vivir adentro (J3).

En [la escuela privada] no tenemos mucha problemática en cuanto a lo social. Los chicos lo que tienen es muy buen poder adquisitivo, que es importante, vos si le pedís un libro por ahí sí te lo llevan... El material que les pedís te lo llevan, no hay muchos problemas... [...] Tenemos obviamente problemas de padres separados [...] familias ensambladas. Pero en cuanto al nivel de los chicos tanto adquisitivo como familiar es bueno, digo comparado con lo que uno vive en una escuela pública. [...] Ahí tenemos chicos con problemas de drogadicción, chicos con problemas de vandalismo, que roban... entonces es como que uno ve dos realidades diferentes cuando trabaja en la privada y en la pública' (H2).

La caracterización de la población escolar es realizada, de manera preponderante, a partir de la percepción de la inserción socioeconómica de los grupos familiares de los estudiantes. La mirada de los docentes sobre esos niveles socioeconómicos se define generalmente desde la carencia de atributos correspondientes a otros, estableciendo cierta correlación lineal entre el sector social de procedencia, las configuraciones familiares y el acompañamiento familiar a las propuestas escolares. La mayor parte de los docentes manifiesta su preocupación por las características de los grupos familiares, a las que, o bien atribuyen actitudes de acompañamiento y contención, o bien de abandono y desinterés. De esas actitudes parece depender el éxito o el fracaso de la tarea educativa:

Hay chicos que nosotros consideramos dentro de un rango normal, que están bastante bien en la educación y en valores, y después hay chicos que tienen diferentes problemáticas familiares... Problemáticas sociales, problemas de aprendizaje... Diferentes problemáticas que nosotros tenemos que atender. Y lo que se ve mucho, sobre todo en los primeritos15, que es la base, es que hay que apuntalar mucho, y la dejadez de los padres (G1).

15 Se refiere a los alumnos de primer grado, de una edad teórica de 6 años. 
Yo trabajo a la mañana donde hay familias "desambladas" [sic], muchas madres solteras con chicos que no mandan a los chicos más grandes a la escuela porque tienen que cuidar a los hermanos porque ellas trabajan, y los chicos van la mayoría por voluntad propia. Si bien ellos van y se sientan y no hacen nada, ellos quieren estar ahí. Entonces uno tiene que buscar la manera de atenderlos. [...] En la escuela de la tarde es distinto. Es inclusive por la ubicación de la escuela, hay acompañamiento de los padres, se preocupan (B1).

Son niños de los cuales, por sus característica particulares, tenemos que "remar" 16 con la situación familiar que se vive, de asistencia, en muchos aspectos. Por ejemplo: hay niños que se me descomponen a las dos o tres de la tarde, y "¿qué te pasó?”; “¿cuál fue el problema?” Y, son niños que se levantan al mediodía, evidentemente a la mañana no desayunan, no almuerzan, entonces la escuela les tiene que proveer una taza de leche como para que ellos puedan seguir su rutina. No es tipo de pobreza, no pasa por la situación económica, sino que pasa por la desatención de la familia en sí, la contención que el niño requiere y no le están brindando (A1).

Las familias son muy colaboradoras, son de estar presentes, también se nota por ahí en el turno tarde que hay más presencia de los padres y en la mañana la realidad es que trabajan y por ahí los chicos están más solitos. [...] Tenés grupos muy tranquilos, los papás colaboran bastante en lo que se les solicita colaborar. Por ahí tenemos uno, dos o tres en cada grupo de niños que tienen dificultades, pero bien' (D2).

He trabajado de cuarto a séptimo, y se ve el desfasaje en cuanto a la poca participación de los papás, incluso en el seguimiento de los aprendizajes del alumno. [Esta es la] Primera vez que estoy en primer grado y se nota mucha participación. [...] Después he vivenciado que se pierde completamente, y en los últimos años el chico está muy abandonado, en cuanto a lo afectivo y en cuanto al acompañamiento de su aprendizaje. Lo primero que marca a un niño es su familia y el entorno de la familia (K2).

16 Refiere a una actividad realizada con esfuerzo
En estos testimonios, los docentes se manifiestan sorprendidos y desconcertados ante la ausencia de los sentidos históricamente asignados a las relaciones entre padres y docentes, entre familias y escuelas, para la integración social y económica en la sociedad moderna, en la que habitualmente la escuela y los docentes eran vistos como aliados necesarios para el ascenso social. En la voz de algunos docentes, se enfatizan particularmente las carencias de algunos grupos sociales, entre los cuales predominan los inmigrantes recientes:

En la escuela la mayoría de los niños son carenciados, tenemos un porcentaje de bolivianos y gitanos. No son la mayoría, pero es importante la cantidad, por ejemplo, los bolivianos la mayoría son analfabetos, hacen solo lo que los maestros les piden. Por ejemplo, ellos viven con sus abuelos y padres y hablan quechua nada más, y me ha pasado que le voy a enseñar al niño y no saben castellano, no están informados, no leen bibliografía, no manejan información diaria ni los periódicos, entonces hay un nivel bajo de aprendizaje y económico (E1).

Los tratamos de incluir [a los niños bolivianos], citamos a los padres, no son todos de la misma condición, hay algunos alfabetizados y de buena condición económica. Con ellos trabajamos los valores como el resto. En lo que sí tenemos problemas es en lengua, porque ellos no articulan bien para hablar. Con respecto a los gitanos ellos son analfabetos, por ejemplo, viene una gitana para anotar a un chico para segundo, le decís que no hay lugar y dice: bueno, anótamelo en cuarto. Esos padres no se preocupan, no traen libros (E1).

En la otra escuela, a la mañana, si bien no hay zíngaros, es más o menos lo mismo. No hay un acompañamiento de los padres. Los chicos, la mayoría van por voluntad propia [...] y ya algunos andan en la delincuencia, alcohol y drogas, entonces, es muy difícil (B1).

En estas expresiones, las diferencias culturales se conciben como carencias y limitaciones atribuidas a comunidades étnicas en forma global. Allí se advierte la circulación de visiones estigmatizantes 
Formación ética y ciudadana. Vicisitudes de la transformación curricular en la Patagonia Argentina

Isabelino A. Siede, Elizabeth Guglielmino, Julia Alcain, Gabriela Fernández y Diana Guinao

y estereotipadas sobre algunos conjuntos sociales, sustentadas en la jerarquización -y al mismo tiempo- desvalorización de determinados saberes y cánones culturales. Cabe preguntarse cuánto de esta descalificación cultural respecto de los saberes que portan determinados grupos sociales explicaría, en parte, la falta de acompañamiento a la que aluden los docentes en otros tramos.

$\mathrm{Al}$ indagar sobre la importancia de la formación ética y ciudadana, sus propósitos y sus contenidos, la mayoría de las respuestas apuntan a la transversalidad del espacio, sin dar cuenta de su significado y anclaje en las prácticas, sino más bien en aras de explicar su indefinición y ausencia de peso institucional. Las prácticas reales del espacio curricular dependen, como lo manifiestan los entrevistados, de la decisión personal de cada docente:

Nosotros a veces conversamos que sería bueno tener el área de formación ética porque por ahí no todos los docentes están dispuestos a querer trabajar con esto de los valores, con inculcar los valores. (B1).

Es una cuestión también muy personal de uno, de inclusive, lo que yo traigo desde niña, cómo me lo han enseñado, que es lo que me atrajo, que es lo que yo leo, aparte, no me preguntes de autores porque yo soy de leer hasta los diarios, así que... ni me fijo en los autores. Es un error mío, pero sí de leer y buscar cosas y mostrárselas a ellos. Sí, yo sí, yo lo trabajo. No vengo y digo: "Hoy vemos formación ética” pero cuestiones sí, yo le doy importancia. Así me criaron a mí. [...] Todo ese tipo de cosas que a nosotros nos enseñaron de otra manera, como que se dejó de lado. Yo no sé, yo soy más hincha, quizá. Por ahí prefiero dejar de enseñar dos más dos y... (J3).

Formación ética y ciudadana pareciera ser un espacio que no existe a menos que se cuente con la buena voluntad del docente que asuma este desafío como propio. $\mathrm{Y}$ en esa entrega lo que se transmite son las convicciones subjetivas del propio educador. Ocuparse o no de la formación ética y ciudadana dependería de la relevancia que tenga este asunto para cada docente en su peculiar forma de con- cebir el mundo. El docente, en este sentido, no es agente público, sino una especie de madre o padre que decide qué es valioso transmitir a sus hijos: se licua lo público en las bienintencionadas iniciativas privadas.

Entre los contenidos de la formación ética y ciudadana, dos cuestiones aparecen recurrentemente en las entrevistas como contenidos casi exclusivos: los valores y el buen comportamiento (que frecuentemente se desliza hacia los buenos modales). En ambos casos, la fuente de legitimación de lo que se enseña es un difuso pasado de las escuelas y de las familias, usualmente ejemplificado en el pasado personal de los docentes. Las afirmaciones que por lo general acompañan a esta perspectiva subrayan la pérdida de valores o la crisis de valores por la que estaríamos atravesando como sociedad. Allí cobra sentido la visión del otro como carente que mencionamos más arriba, al analizar las representaciones sobre los grupos familiares. Las actitudes y valoraciones de las familias aparecen, en la voz de los docentes, como el principal obstáculo para su tarea:

Eso del acompañamiento de la familia y que desde la familia no se trabajan los valores, el respeto por el otro, por uno mismo [...]. Por ejemplo, tenemos familias zíngaras. Ellos no tienen nuestros mismos valores. De hecho, les da lo mismo que el chico aprenda o no, que vaya a la escuela o no... No hay un acompañamiento ni una misma mirada, ni un mismo discurso desde la escuela y la casa. Son discursos totalmente distintos. (B2).

En general los valores en la sociedad están muy vapuleados, entonces es difícil poder formarlos en valores a los chicos [...]. A veces es muy difícil porque por ahí vienen padres que aceptan la situación, que acompañan y para mejorar y por ahí hay padres que no tenés esas respuesta ni ese apoyo y que, por ahí, no te entienden lo que vos querés que entiendan, como que tienen otros valores las familias ahora. [...] Yo lo que noto es que la familia que generalmente está en contra, yo noto que no tienen valores tradicionales. (C1).

Yo no veo un problema de enseñar una disciplina como la ética ciudadana, lo que sí rescato es que 
ha desaparecido en algunas familias esto de ser ético y ciudadano, y esto no quiere decir que uno coma santos todo el día, sino valores primordiales: el respeto... el respetar horarios, el respetar valores, el respetar al par, el respetar al mayor. $\mathrm{Y}$ la escuela es una institución moderna, que no ha cambiado, desde el tiempo en que ha nacido. (I1).

Por ejemplo, tenemos un nene [que] no sé porque saca cosas, las roba. Nosotros no le decíamos directamente: "Eso es robar", o no le decimos: "Sos un ladrón” pero ya los nenes lo están digitando así como ladrón, como el que saca cosas. El nene no necesita las cosas porque viene de una familia que el padre trabaja bien, la señora también es una familia bien, normal, constituida de lo que nosotros decimos familia tradicional. (C2).

Predomina entre estos docentes una visión objetivista de los valores como algo absoluto y estático, cuyo esplendor está en el pasado y que, en el presente, se pierden o son vapuleados, que merecen ser recuperados y protegidos. Asimismo, atribuyen a las familias una responsabilidad indelegable en la transmisión de los mismos como condición de posibilidad del trabajo pedagógico escolar. En la tradición de Durkheim (1973) y de Berger y Luckmann (1994), la formación escolar es un complemento de lo que se inicia en la casa: una socialización homogénea y legítima, responsable de educar en valores tradicionales, sin lugar para diversas socializaciones posibles ni diferencias culturales dentro de una misma sociedad. En esa línea, las miradas de los docentes expresan resabios del contrato fundacional del sistema educativo, establecido sobre un conjunto de reglas y normas en adherencia a determinados valores constitutivos del proyecto moderno: la expansión de la escuela, como hemos visto, se sustentó en principios y valores de fuerte sentido moralizador. Se advierte, en las voces de estos docentes, las resistencias que operan en forma explícita e implícita sobre los sujetos que, con sus particularidades y diferencias, interpelan a la escuela:

Las sociedades van cambiando y los valores se han ido perdiendo: el respeto... Hay un montón de cuestiones que quizás antes era enseñado en la familia, hoy por hoy se están perdiendo y cuesta mucho hacer el trabajo solo desde la escuela. ¿Entendés? Porque al pibe17 no le importa y a la familia tampoco, y a la sociedad tampoco. Entonces vos estás en contra de todo eso, tratando de enseñar algunas cuestiones. (C1).

Los famosos valores y modales que se perdieron. $\mathrm{O}$ no es que se perdieron, yo creo que cambiaron de orden. Hay otras cosas que se mantienen iguales. Como que se ha deteriorado bastante el "por favor", el "gracias", el "permiso", bueno "te explico", "te cuento", "te escucho", "hablo", o sea, "te respeto", ayudo, ser solidario. (J3).

El maestro constituiría el guardián de los valores perdidos, o bien el transmisor de los valores reificados, objetivos, indiscutibles que habitan inmutables en el firmamento, y que es necesario volver a encontrar. Los relatos acerca de su práctica dan cuenta de que transmitir valores, o inculcarlos constituiría la principal tarea de la formación ética y ciudadana. Los discursos de los docentes, en este sentido, se inscriben en la tradición de Durkheim, que Puig Rovira (1996) denomina educación moral como socialización: tendencia basada en la adaptación heterónoma a un sistema de normas y valores absolutos en los que los sujetos en formación no tienen intervención, sino más bien la tarea de internalizarlos. El propósito de la socialización no es pensar ni construir a la sociedad, sino incluirse en ella:

Según esta perspectiva existen una serie de valores y normas de conducta que deben ser transmitidos de una generación a la siguiente de forma inapelable. Dichos modelos y normas se plantean como incuestionables $y$, por lo tanto, ajenos a cualquier modificación o replanteamiento (p. 21).

El maestro que se refiere a lo que está bien y lo que está mal es un ejemplo de esta perspectiva, que transmite un absoluto moral y entiende la autonomía como adaptación heterónoma. Lo que está bien y está mal no es algo a construir, ni a debatir, sino a descubrir. En algunos fragmentos de las entrevistas

17 La palabra "pibe" se emplea en el ámbito rioplatense para referirse a un niño. Puede tener un sesgo peyorativo, pero no parece tenerlo en este caso, donde solo expresa familiaridad. 
Formación ética y ciudadana. Vicisitudes de la transformación curricular en la Patagonia Argentina

Isabelino A. Siede, Elizabeth Guglielmino, Julia Alcain, Gabriela Fernández y Diana Guinao

realizadas a los docentes, indagando sobre los contenidos de la formación ética y ciudadana, aparece esta concepción del valor como algo inmutable, objetivo, que es necesario reconocer, preservar y transmitir. Eso se expresa en el tipo de actividades propuestas para la enseñanza, en las escasas ocasiones en las que algún docente las menciona:

Generalmente nosotros tratamos de buscar algunos cuentos que se reflejen con alguna problemática que estaban pasando en el aula. Entonces ellos mismo se van dando cuenta y vamos viendo qué es lo que se debe hacer y lo que no se debe hacer, qué es lo que está bien y qué es lo que está mal. (B1).

Los docentes que manifiestan realizar alguna actividad de enseñanza apelan a textos de ficción como fuente de valores y herramienta para una transmisión comprensible. En la voz de estos docentes, las escuelas comparten una imagen de una escala armoniosa y ordenada de valores, que guiaría sus acciones formativas:

Trato de buscar los textos que busco que tengan algún valor para destacar, ahora yo estoy dando una novela que tiene que ver con el racismo con el tratar del desprecio, habla del desprecio que tenía una nena chiquita porque era negrita, entonces hablamos y desde ese lado yo lo abordo. (C3).

Y creo que es justamente formar ciudadanos. $\mathrm{O}$ sea, que cuando los chicos crezcan que crezcan con estos valores, de respeto, de cuidado y demás hacia la sociedad y que puedan ser ciudadanos íntegros, los que puedan insertarse en la sociedad en cuanto a trabajo y demás. (B2).

Después de la lectura generalmente comentábamos cuál es el valor que surge y después otra situación que también podemos trabajarla en la que hay algún valor que ha sido vapuleado, entonces este lo trabajamos y tratamos de que quede cerrada la idea de lo que nosotros queremos que entiendan de ese valor. (C2).

Para nosotros lograr en el niño la formación de los valores: respeto, solidaridad, compañerismo. Bueno, tratamos de buscar que los niños sean respetados respetando, ¿no es cierto? Inculcando solidaridad, el cuidado, cuidarse y, bueno, todo lo que son los valores. (E1).

En mi escuela también no se trabaja como un contenido aislado, sino algo transversal en la que uno, a través de cuentos o textos, hace ver a los chicos estos valores del respeto hacia el otro, hacia las pertenencias, hacia las personas, hacia las opiniones ajenas. (B2).

El uso de textos ficcionales y relatos con moraleja amerita indagaciones futuras, a fin de caracterizar con mayor precisión la concepción didáctica de los docentes y los contenidos efectivamente desplegados en ese trabajo.

Entre los valores más mencionados están la solidaridad y el respeto, aunque no siempre parecen aludir a los mismos contenidos en la voz de diferentes docentes. Posteriores lecturas nos permitirán avanzar en ese análisis más sutil. Es difícil establecer el fundamento filosófico de las concepciones que los docentes expresan sobre la ética y los valores. En unos pocos casos hay alusiones más o menos sutiles a la formación religiosa que se desliza desde las prácticas personales de los docentes a su actuación profesional:

Antes a la mañana trabajaba solamente en el Juan18, pero me ayudó muchísimo esto de saber la vida de Don Bosco, porque he trabajado con chicos sufridos, chicos de la cárcel, chicos que necesitan contención y ahora es como que yo lo aplico. No lo aplico en la escuela donde estoy ejerciendo que es el Juan, donde aprendí la vida de Don Bosco, pero me sirve para la escuela pública, porque en la escuela pública se ven los verdaderos hijos de Don Bosco y ahí tenés chicos problemáticos que no los ves en el salesiano. (H2).

Otro tópico que resulta pertinente destacar, a partir de una primera lectura de las entrevistas, es la vinculación de la formación ética y ciudadana con los buenos modales o buen comportamiento, con frecuencia asociados, e incluso identificados, con los valores. Se trata de modales heredados de cierta tradición civilizadora que erige las pautas

18 Colegio privado, de orientación católica. 
relacionales de la clase media urbana como patrón de comportamiento exigible en ámbitos públicos y privados. La diferencia con las pautas familiares es denunciada por los docentes como una falencia de la crianza doméstica:

Por ahí, a veces, uno peca por ser la "maestra ciruela", de decir, "llegan tarde" y pegan un portazo a la puerta, pasan, se sientan: "No, mira, retírate, salí, golpeá, pedí permiso". Decir: "Buenos días". Sí, son esas pequeñas cosas diarias que uno todos los días lo va reforzando, pero bueno, sería bueno que todos fuéramos multiplicadores de lo mismo. (B1).

Desde que un chico, si tiene que ir a pedir algo a otra aula, de que tiene que golpear la puerta, pedir permiso, saludar, sí. Porque es algo que ellos no lo tienen incorporado, no vienen de la casa con eso incorporado. (B1).

Todos los días se trabaja, desde el saludo, desde el "buen día", desde valores que son primordiales, ¿no? Porque, por ahí, hoy en día, capaz que te cruzas con una persona por la calle y no te saluda, por el ánimo que tiene o que esto, que lo otro, pero, bueno, como siempre digo, un "buen día", un "qué tal" o un "buenas tardes" te abre las puertas en todos lados. Creo que desde ahí nosotros lo trabajamos muy fuerte, eso destaca mucho, mucho, mucho a los chicos de esta escuela. (I1).

"No se habla", "hay que levantar la mano", "respetar a la seño", "respetar al compañero", "saludar a los porteros", "saludar a la directora", "llegar a horario", ¿viste? El cuaderno no olvidarlo en la casa. Todas unas normas que ellos mismos te las dicen. Y después en el año, cuando surge algo, vos vas al cartel que nosotros lo tenemos pegado en la pared. "A ver, ¿qué dice acá?". (J3).

Esta preocupación por los buenos modales puede interpretarse como residuo de una vertiente de educación moral entendida como formación de hábitos virtuosos, que Richard Stanley Peters recrea de la tradición aristotélica (Puig, 1996). Según esta vertiente, el propósito de la educación moral es que el sujeto transforme sus conductas cotidianas y adquiera virtudes o hábitos considerados buenos por la sociedad: "No se trata de garantizar compor- tamientos 'buenos' pero aislados, sino de conseguir que el educando actúe correctamente 'de forma automática. O dicho de otra forma más suave, se puede facilitar la conducta correcta a fuerza de repetición y del ejercicio" (p. 63).

Cuando los docentes afirman que formación ética y ciudadana tiene que ver con el cambio de conductas y con portarse bien, desmerecen toda apelación al razonamiento, al pensamiento crítico y a la participación activa de los alumnos en la justificación y evaluación de sus conductas. Lo que recomienda el maestro está ligado a la forma correcta y legítima de comportarse. La buena conducta es la traducción en acciones de la cultura legítima.

Algunos fragmentos de las entrevistas exponen sin ambages la violencia simbólica que ejerce la escuela como instancia hegemónica: el maestro es portador de la cultura oficial, y esa cultura oficial incluye no solo lo verdadero y lo correcto, sino también lo bello y lo bueno. Varios docentes dan ejemplo de cómo suavizan sus intervenciones para manipular las decisiones de los alumnos sobre su vestimenta, sus modales o sus elecciones cotidianas:

Cuando entiendo la situación que vive, bueno, trato de llevar a lo que yo quiero que él realice y darle consejos: "Mirá, tenés que estudiar, trata de arreglarte, tratá de cambiar de...". Conductas que no le sirven a él y le sirven para él relacionarse con los otros. En esto estoy y, bueno, es un trabajo diario digamos de tratar de dar consejos, de escuchar, porque si nos plantamos en "esto no podés" creo que no es la forma de construir con el alumno. (D2).

Entonces el maestro por ahí está diciéndole: “¿Por qué no cumple?” o “¿Por qué no se saca la capucha?"19. O sea, él nunca se saca la capucha. Está toda la clase con la capucha. [...] Entonces, si

19 Una capucha es una parte de una prenda de vestir que cubre buena parte de la cabeza y todo el cuello. Puede ser utilizada como protección contra el frío intenso o como moda. En el medioevo, ese tipo de caperuzas estaban asociadas a los hábitos monásticos, pero actualmente los jóvenes las usan como una expresión sutil de rebeldía, pues algunos delincuentes las usan para dificultar su identificación. En cualquier caso, esta u otras explicaciones son solo interpretaciones posibles sobre la moda y el vestuario de los jóvenes. 
Formación ética y ciudadana. Vicisitudes de la transformación curricular en la Patagonia Argentina

Isabelino A. Siede, Elizabeth Guglielmino, Julia Alcain, Gabriela Fernández y Diana Guinao

vos le insistís constantemente y estás como que... hostigándolo, él no quiere y te hace la contra. En cambio, si vos lo tenés tranquilo y le decís, por ejemplo... [...] Él, por ejemplo, los primeros tiempos iba vestido con la capucha y los pantalones cortos hasta acá así, así fuese invierno, ¿no? $Y$ él con los pantalones cortos a media canilla. Entonces un día fue de jeans. Entonces le digo: “¡Ay, Ezequiel, qué lindo qué estás! ¡Mira qué lindo que has venido hoy", porque [estaba] todo arregladito, la capucha para atrás! Le digo: “¡Qué lindo que estás, Ezequiel!". (F2).

¿No? Desde ese día no se sacó más el jean. Capaz que era el único jean que tenía, pero va con jean y eso lo hace ver más arregladito (H2).

En estas alusiones a la ropa, a los gestos y a las palabras adecuadas, se aprecia una arbitrariedad cultural que los docentes imponen de modo ostensivo o sutil. ¿Es indiscutible en el relato que el jean es mejor que el pantalón a media canilla? Que un alumno vea la forma correcta de arreglarse, ¿es una tarea docente legítima o avasalla la identidad y las elecciones de cada alumno?

En estos fragmentos se puede apreciar un currículo efectivo bastante alejado de las prescripciones reseñadas más arriba y continuador de prácticas y creencias de la escuela tradicional. No nos referimos a la violencia simbólica del currículo explícito, que representa, en gran medida, algunos consensos públicos, sino a preferencias personales que se tornan oficiales e invisibles al ser proferidas desde la autoridad escolar.

\section{Preguntas e implicancias de esta investigación}

Las primeras lecturas de estas voces de los docentes nos han permitido detectar algunos contrastes y contradicciones entre:

- Una prescripción curricular descontextualizada y una práctica educativa que atribuye sus mayores limitaciones al contexto socioeconómico y cultural.

- Un área de conocimiento que planteaba la intención de someter a juicio crítico los discur- sos morales dominantes y unas prácticas escolares en las que esos juicios son naturalizados y transmitidos como contenido de enseñanza.

- Una expectativa curricular de aportar a la transformación de la sociedad a través de la educación ciudadana y una expectativa del cuerpo docente de que la comunidad recupere valores perdidos y acompañe la educación escolar con el ejemplo cotidiano.

- Una educación ética que se presentaba originalmente como espacio de construcción de lo público y unas modalidades de enseñanza en la que cada docente enarbola sus propias creencias y costumbres como bandera incuestionable y exige a sus alumnos el sometimiento a ese conjunto representacional.

Al relevar las descripciones y justificaciones de los docentes sobre sus prácticas de educación moral se puede apreciar una fuerte impronta moralista, que da continuidad a algunas tradiciones civilizatorias, higienistas y homogeneizantes desarrolladas desde los orígenes del sistema educativo provincial, tal como mencionamos al inicio. Lo que circula como formación ética y ciudadana en las escuelas parecería ser parte, no obstante, del currículo oculto, que es la cultura que la escuela transmite e inculca sin explicitar. Mediante una operación que constituye al sistema educativo como depositario de la cultura oficial, el capital simbólico y cultural que la escuela transmite es catalogado positivamente como la cultura legítima: es útil, correcto, moral e indiscutible. Hay en los relatos la certeza de que el mundo -y las personas- deberían ser de un modo y no de otro. Se delimita una cultura al inculcar que no se puede deducir de ningún principio universal ni lógico. Tampoco, en este caso, se deduce de la prescripción jurisdiccional.

El diseño curricular provincial no parece ser un documento de trabajo de uso corriente en la vida cotidiana de la escuela. También se advierte que los enunciados del diseño curricular, que pretendían la formación de sujetos autónomos, críticos y solidarios, entre otros adjetivos, han tenido escasísimo impacto en las prácticas. En gran medida esto 
se explica por las débiles políticas de formación y capacitación docente, en contraste con la autonomía que la propuesta curricular esperaba de ellos. La definición transversal de este espacio curricular contribuyó a diluir la especificidad disciplinar e interdisciplinar de los contenidos prescriptos. Como contrapartida, resulta necesario que los docentes conozcan teorías del desarrollo moral y del conocimiento social para construir estas prácticas de enseñanza. En el trascurso de lo que se viene investigando resulta significativa la ausencia de formación en esta área, donde los docentes denuncian que no se habilitaron espacios para analizar y debatir los fundamentos pedagógicos-epistemológicos que le otorgan sentido a la nueva área.

En este marco, resulta de interés recuperar los aportes de André Chervel (1991), quien investigó la historia de la gramática como contenido escolar, acuñó la noción de disciplina escolar para enfatizar la relativa autonomía del conocimiento escolar respecto al ámbito académico. Este autor advierte la relevancia de los propósitos y las funciones escolares, tal como las entienden sus miembros, como muro de contención o tamiz de procesamiento de las innovaciones curriculares:

En este punto se puede apreciar el peso y la eficacia real de la tradición. Cuando los objetivos se vienen imponiendo a la escuela desde décadas $y$, con mayor razón, desde siglos antes, se transmiten entonces a los enseñantes a través de una minuciosa tradición pedagógica y didáctica, compleja y hasta sofisticada a veces. Y no es excepcional ver cómo el conjunto de las prácticas pedagógicas acumuladas en una disciplina acaba por ocultar a muchos enseñantes algunos de los objetivos últimos que deberían perseguir. (Chervel, 1991, p. 76).

En tal sentido, su mirada sobre la inclusión de nuevos contenidos se emparenta con la noción de gramática escolar, una analogía utilizada por Tyack y Tobin (1994) para designar las estructuras profundas, normas y costumbres que se comparten de manera implícita y que organizan el sentido del trabajo escolar. Así como la gramática de la lengua organiza el significado del habla, la gramática escolar organiza las prácticas escolares. Y es en ella donde se asientan o son repelidas las innovaciones propuestas. En este caso, esa gramática escolar subyacente parece haber deglutido todo intento de renovación del área de formación ética y ciudadana, relegándola al olvido o subsumiéndola en las tradiciones moralizantes preexistentes. Trabajos de evaluación de los procesos curriculares de educación ciudadana, como el de Cox et al. (2014), comparan

[...] los contenidos de diversos currículos nacionales de educación ciudadana, con el propósito de establecer bases para la discusión y discernimiento acerca de la relación de sus prescripciones con requerimientos de la preparación para la vida juntos del presente, y más concretamente, con la pregunta acerca de cómo tales prescripciones están respondiendo a las necesidades de formar para la dimensión política de este vivir juntos (p. 5).

Sin embargo, el mero cotejo de prescripciones podría contribuir a formular una imagen muy alejada de lo que efectivamente ocurre en las escuelas de la región. La identificación de la prescripción curricular con el currículo supone una traslación demasiado esquemática y mecánica de las intenciones de política educativa a los criterios de intervención didáctica en la cotidianeidad de las aulas. En este sentido, advierte De Alba (1995):

[...] el currículum es la síntesis de elementos culturales, esto es, de conocimientos, valores, creencias, costumbres y hábitos, que conforman una determinada propuesta político-educativa. Estos elementos culturales se incorporan en él no solo a través de sus aspectos formales-estructurales, sino también por medio de las relaciones sociales cotidianas en las cuales el currículum formal se despliega, deviene práctica concreta (p. 60).

Las nuevas definiciones curriculares que podrían adoptarse tras varios años de vigencia de este diseño requieren un relevamiento cualitativo de lo que los docentes han hecho bajo el marco de sus enunciados. El estudio y la valoración de las prácticas pedagógicas efectivamente vigentes es una de las vías principales de comprensión cualitativa de los procesos formativos que despliegan las instituciones, pero se ve seriamente limitado por los enfoques sobre calidad de la enseñanza escolar: 
Formación ética y ciudadana. Vicisitudes de la transformación curricular en la Patagonia Argentina

Isabelino A. Siede, Elizabeth Guglielmino, Julia Alcain, Gabriela Fernández y Diana Guinao

En las dos últimas décadas ha cobrado relevancia el debate sobre la calidad de la educación. Una sospecha sobre lo que ocurre entre los muros de la escuela ha estado presente en el origen de estas preocupaciones. También la convicción de que es necesario mejorar los aprendizajes que alcanzan los estudiantes en todas las áreas del conocimiento. Desafortunadamente, buena parte de los actuales debates sobre la calidad, pasan casi exclusivamente por las mediciones de conocimientos o habilidades por medio de pruebas estandarizadas aplicadas a los estudiantes en algunas pocas materias. Si bien es mucho más que lo que teníamos en el pasado, este enfoque de la calidad resulta reduccionista en extremo, ya que no considera muchas áreas de conocimiento y margina los aspectos no cognitivos del aprendizaje escolar. (Botinelli, 2013).

El relevamiento realizado abarca casi todas las escuelas primarias del norte de la provincia de Santa Cruz y sus rasgos no pueden atribuirse mecánicamente al conjunto. Sin embargo, tenemos fuertes sospechas de que la ampliación de la muestra no arrojaría resultados muy diferentes. Para ahondar en el análisis, nos interesaría intercambiar informaciones y lecturas con equipos que realicen indagaciones semejantes en otras regiones de la Argentina y también en otros países de América Latina, a fin de comprender más cabalmente los efectos reales de las oleadas de renovación curricular.

En este caso, la mayoría de los testimonios dan cuenta de una presencia marginal o nula de la prescripción curricular, al mismo tiempo que los docentes despliegan una variedad de posicionamiento ideológicos y morales en sus enseñanza habituales. La expectativa original del área de formación ética y ciudadana, que buscaba intervenir en el currículo oculto para visibilizarlo y someterlo a la validación pública, para denostar su sesgo conservador y potenciar su aporte crítico, parece haber fracasado rotundamente. En el contraste entre las viejas prácticas de educación moral escolar y los nuevos ímpetus de una formación ética de carácter crítico, todo indica que la primera se mantiene incólume en las escuelas analizadas:
La educación moral (en sentido tradicional) se ha ocupado, en la Argentina y en países vecinos, de transmitir una moral. La formación ética no se identifica con este tipo de educación moral. No implica transmitir (menos aún, inculcar) una tradición. Es crear condiciones para que los estudiantes puedan armar, de manera autónoma, sus propias matrices de valores, construir de manera conjunta una serie de acuerdos básicos en pos de una convivencia justa, justificar sus propias acciones y juzgar críticamente las de los demás, ponerse en el lugar del otro para comprenderlo desde dentro, salirse de su propio yo, descentrarse, para entrar en la esfera de los otros y ampliar su visión del mundo. (Schujman, 2007, p. 72).

En la puja que caracteriza la construcción efectiva del currículo escolar no se advierte la presencia de un trabajo de articulación institucional que sirva de encuadre, por lo que queda supeditado a las representaciones y creencias que tienen los docentes respecto de estas cuestiones. En estas prácticas de enseñanza, como en otros aspectos vinculados con las condiciones edilicias y laborales, la escuela se muestra como un páramo desolado, en el que solo la buena voluntad puede operar ante las inclemencias de lo cotidiano. Así lo afirma una de las docentes entrevistadas: "Por suerte estamos entre todos tratando de sacar [adelante] la escuela, poniendo la mejor voluntad que se puede" (C4).

Pero la voluntad no basta. El análisis que realizamos, si bien se basa en la voz de los docentes y no los excluye de responsabilidades sobre su actuación profesional, apunta a vislumbrar las modulaciones efectivas de las políticas curriculares e institucionales que se encaraman detrás de enunciados elegantes y dejan a los actores del sistema educativo a la intemperie.

\section{Referencias bibliográficas}

Baranda, M.; Quiroz, G. y Marichelar, J.C. (2004). Formación ética y ciudadana. En: Educación General Básica. Diseño Curricular. Río Gallegos: Consejo Provincial de Educación.

Berger, P. y Luckmann, T. (1994). La construcción social de la realidad. Buenos Aires: Amorrortu. 
Bottinelli, L. (octubre de 2013). 30 años de educación en democracia. [En prensa]. Le Monde Diplomatique, 172.

Chervel, A. (1991). Historia de las disciplinas escolares. Reflexiones sobre un campo de investigación. Revista de Educación, 295, 59-111.

CFCyE (Consejo General de Cultura y Educación) (1994). Resolución No. 37/94 del Consejo General de Cultura y Educación. Buenos Aires. Julio de 1994.

CFCyE (Consejo General de Cultura y Educación) (1995). Resolución No. 40/95 del Consejo General de Cultura y Educación. Buenos Aires. Junio de 1995.

Cox, C.; Bascopé, M.; Castillo, J.; Miranda, D. y Bonhomme, M. (2014). Educación ciudadana en América Latina: Prioridades de los currículos escolares. IBE Working Papers on Curriculum Issues $\mathrm{N}^{\circ}$ 14. Ginebra, UNESCO Oficina Internacional de Educación. Recuperado de: http://www.ibe.unesco. org/fileadmin/user_upload/Publications/Working_ Papers/education_ciudadana_ibewpci_14.pdf

Cullen, C. (1996). Autonomía moral, participación democrática y cuidado del otro. Bases para un currículo de formación ética y ciudadana. Buenos Aires: Novedades Educativas.

De Alba, A. (coord.) (1995). Postmodernidad y Educación. México: CESU-UNAM-

Díaz, R. (2001). Trabajo docente y diferencia cultural. Lecturas antropológicas para una identidad desafiada. Buenos Aires: Miño y Dávila.

Durkheim, E. (1973). La educación moral. Buenos Aires: Schapire.

Hillert, F.M. (2011). Políticas curriculares. Sujetos sociales y conocimiento escolar en los vaivenes de lo público y lo privado. Buenos Aires: Colihue.

Jackson, P.; Boostrom, R. y Hansen, D. (2003). La vida moral en la escuela. Buenos Aires: Amorrortu.

Lionetti, L. (2007). La misión política de la escuela pública. Formar a los ciudadanos de la república (1870-1916). Buenos Aires: Miño y Dávila.

Puig, J.M. (1996). La construcción de la personalidad moral. Barcelona: Paidós.

Puiggrós, A. (1994). Sujetos, disciplina y curriculum en los orígenes del sistema educativo argentino. Buenos Aires: Galerna.

Puiggrós, A. (1997). La otra reforma. Desde la educación menemista al fin de siglo. Buenos Aires: Galerna.
Reato, C. (2012). Disposición Final. La confesión de Videla sobre las desapariciones. Buenos Aires: Sudamericana.

Schujman, G. (2007). Concepciones de la ética y la formación escolar. En: G. Schujman e I. Siede (comp.). Ciudadanía para armar. Aportes para la formación ética y política. Buenos Aires: Aique.

Siede, I. (2007). Educación para el desierto argentino. En: I. Siede. La educación política. Ensayos sobre ética y ciudadanía en la escuela (pp. 65-88). Buenos Aires: Paidós.

Tedesco, J. (1986). Educación y sociedad en la Argentina (1880-1945). Buenos Aires: Solar.

Trilla, J. (1992). El profesor y los valores controvertidos. Neutralidad y beligerancia en educación. Buenos Aires: Paidós.

Tyack, D. y Tobin, W. (1994). The 'grammar' of schooling: Why has been so hard to change. American Educational Research Association 31(3). 